\title{
Influence of the stainless steel 321 (X18H10) structure on pitting corrosion in low-mineralized water. Inhibiting effect of sulfate and hydrocarbonate ions
}

\author{
A.I. Shcherbakov, * I.V. Kasatkina, V.E. Kasatkin, I.G. Korosteleva, \\ V.N. Dorofeeva and L.P. Kornienko \\ A.N. Frumkin Institute of Physical Chemistry and Electrochemistry, Russian Academy \\ of Sciences, Leninsky pr. 31, 119071 Moscow, Russian Federation \\ *E-mail: scherbakov@ipc.rssi.ru
}

\begin{abstract}
The study of two austenitic class stainless steels similar in composition and microstructure to the resistance for pitting corrosion in low-mineralized river and tap water showed that steel 321 (X18H10T) sheet is more resistant than steel 301 (X18H9) pipe. This difference in behavior is due to the presence of different amounts of residual ferrite in these steels, which negatively affects the tendency of austenitic steels to pitting resistance. It is shown that anodic polarization in a solutions containing more than $1.45 \mathrm{mg} / \mathrm{L}$ of chloride ion leads to pitting corrosion. When the chloride ion content is more than $21.4 \mathrm{~g} / \mathrm{L}(3.5 \% \mathrm{NaCl}$, which corresponds to seawater), the steel pits without polarization. The presence of sulfate ions in the solution reduces or prevents the tendency of steel to pitting. The threshold concentration ratio of sulfate inhibitor to chloride activator for pitting protection depends on the activator content. The higher the chloride concentration, the higher the $\mathrm{SO}_{4}^{2-} / \mathrm{Cl}^{-}$ratio is required to inhibit pitting. When the chloride ion content in water is above $100 \mathrm{mg} / \mathrm{L}$, the same amount of sulfate ions is sufficient. At the chloride ions concentrations from $200 \mathrm{mg} / \mathrm{L}$ to $500 \mathrm{mg} / \mathrm{L}$, a twice higher sulfate content is required, and at a chloride concentration of up to $3000 \mathrm{mg} / \mathrm{L}$, it is already 3 times higher. Bicarbonate can slightly increase the tendency of steel to pitting corrosion in the absence or with insufficient amount of sulfate inhibitor. At a higher sulfate content, the negative effect of hydrocarbonate is leveled, even if its concentration is 2-4 times higher than the concentration of the inhibitor $\mathrm{SO}_{4}^{2-}$.
\end{abstract}

Keywords: activators and inhibitors of pitting corrosion, AIST 321 (X18H10T) steel, AIST 301 (X18H9) steel, residual ferrite, low-mineralized water.

Received: November 18, 2020. Published: February 8, 2021

doi: $10.17675 / 2305-6894-2021-10-1-10$

\section{Introduction}

One of the stainless steels features is their corrosion resistance in river and tap water due to spontaneous passivation in these environments. At the same time, in practice, there are several cases of pitting corrosion, the causes of which cannot always be taken into account in advance. This makes it difficult to design products from this class of steels [1-4]. One of 
the necessary conditions for the occurrence of pitting corrosion [2] is the presence of activator ions in the solution. In the presence of these ions, local depassivation of the metal surface is possible, resulting in pitting appearance. This type of defects is extremely dangerous, as it can lead to through fistulas in the metal product with a small total loss of mass. The likelihood of pitting depends on the composition of the alloy, its heat and mechanical treatment and operating conditions: the composition of the medium, temperature, structural features of products, etc. In natural water, the chloride ion $\mathrm{Cl}^{-}$plays the main role of the pitting corrosion activator. Pitting phenomena on stainless steels have been studied in detail in relation to brines of relatively high concentrations and sea water conditions. Most often, studies were limited to a minimum concentration of $\mathrm{Cl}^{-}$not lower than $3.55 \mathrm{~g} / \mathrm{L}$ (which corresponds to $0.1 \mathrm{~N} \mathrm{NaCl}$ ). With a decrease in the $\mathrm{Cl}^{-}$concentration in the electrolyte, the likelihood of pitting decreases. Therefore, for low-mineralized waters, such as river and tap water, stainless steels were recommended for use. As a rule, the chloride content in river waters on the territory of our country does not exceed $100 \mathrm{mg} / \mathrm{L}$. However, near large industrial centers in natural water, a significant increase in the concentration of both chlorides and other salts is possible due to soil salinity.

In the previous work [5], the resistance of the austenitic pipe steel 301 grade $^{1}$ were studied in synthetic river water containing $50 \mathrm{mg} / \mathrm{L} \mathrm{SO}_{4}^{2-}$ and $100 \mathrm{mg} / \mathrm{L} \mathrm{HCO}_{3}^{-}$at the various concentrations of chloride ion. It was found that at the content of $25 \mathrm{mg} / \mathrm{L} \mathrm{Cl}^{-}$, the probability of pitting was about $30 \%$, at $50 \mathrm{mg} / \mathrm{L}$ it increases to $80 \%$, and at $100 \mathrm{mg} / \mathrm{L}$ it achieves $100 \%$.

In this work, we investigated the tendency to pitting of austenitic chromium-nickel steel 321 grade $^{2}$ in fresh water with a content of $\mathrm{Cl}^{-}$ions ranging from $12.5 \mathrm{mg} / \mathrm{L}$ to $3000 \mathrm{mg} / \mathrm{L}$, as well as the effect of the likely accompanying sulfate and bicarbonate anions on this process.

\section{Methods}

Samples of sheet steel 321 grade having a cube shape were threaded to a current - supplying holder sealed in a glass tube. Fluoroplastic spacer prevents the penetration of electrolyte to the contact zone. Before the experiment, the samples were cleaned on sandpaper with final grinding with a grain size of $5 \mu \mathrm{m}$, washed, degreased in a mixture of acetone and alcohol in an ultrasonic bath, and again washed with distilled water. The tendency to pitting susceptibility was determined by the potentiodynamic method based on the pitting potential $\left(E_{\mathrm{P}}\right)$ estimation [6]. Polarization was carried out using an IPC-PRO potentiostat (Russia) at a temperature of $30^{\circ} \mathrm{C}$. A saturated silver chloride electrode was used as a reference electrode, and platinum was used as a counter electrode. All potentials in tables and graphs are relative to a standard hydrogen electrode. The solutions were prepared from puriss. grade reagents in such a way that their anionic and cationic composition was close to natural river

\footnotetext{
${ }^{1}$ Russian Steel grade X18H9.

${ }^{2}$ Russian Steel grade X18H10T.
} 
water. After immersion of the samples in the solution, a corrosion open circuit potentials were established in the range from $0 \mathrm{mV}$ to $+200 \mathrm{mV}$, and subsequently changed insignificantly. After a three-minute exposure at $0 \mathrm{mV}$, the potential sweep was turned on to the anodic direction until the breakdown of the passive film, as evidenced by a sharp increase in the current. Upon reaching the anodic current density of $10-15 \mu \mathrm{A} / \mathrm{cm}^{2}$, which under these conditions was sufficient for the stable identification of pitting, the direction of the sweep was reversed to determine the repassivation potential $\left(E_{\mathrm{R}}\right)$. If no breakdown was observed, then the sweep continues up to +1100 to $+1200 \mathrm{mV}$, which exceeds the equilibrium potential of oxygen evolution in a neutral medium. The $E_{\mathrm{P}}$ and $E_{\mathrm{R}}$ potentials are given in the tables as averaged values of several parallel experiments.

\section{Results and Discussion}

It was shown in $[6,7]$ that there is a certain range of potential sweep rates at which the pitting potential remains constant. Apparently, this is due to the time delay in the onset of pitting due to the finite rate of the chloride ion penetration into the passive film on the metal surface. In the present work, we also determined the influence of the sweep rate on $E_{\mathrm{P}}$.

The study were carried out in a model solution containing $100 \mathrm{mg} / \mathrm{L} \mathrm{Cl}^{-}, 50 \mathrm{mg} / \mathrm{L}$ $\mathrm{SO}_{4}^{2-}$, and $100 \mathrm{mg} / \mathrm{L} \mathrm{HCO}_{3}^{-}$, where the studied steel showed a sufficient tendency to pitting, according to the results of preliminary tests (see Table 1). It can be seen from the results obtained that with an increasing in the sweep rate, the pitting potential also increases. A significant increase in the $E_{\mathrm{P}}$ potential begins at sweeps above $1 \mathrm{mV} / \mathrm{s}$, and at $10 \mathrm{mV} / \mathrm{s}$, a continuous increase in the current is associated with the release of oxygen and is not related to the onset and growth of pits. Therefore, all further experiments were carried out at a potential sweep rate of $0.1 \mathrm{mV} / \mathrm{s}$, which is the closest to the quasi-stationary polarization conditions.

Table 1. Potential $E_{\mathrm{P}}$ of steel 321 grade depending on the potential sweep rate.

\begin{tabular}{cccccccc}
\hline $\boldsymbol{V}, \mathbf{m V} / \mathbf{s}$ & 0.1 & 0.3 & 0.5 & 1 & 5 & 7 & 10 \\
\hline $\boldsymbol{E} \mathbf{P}, \mathbf{m V}$ & 880 & 920 & 930 & 900 & 1010 & 1090 & $>1000$ \\
\hline
\end{tabular}

River water is a multicomponent system containing $\mathrm{Cl}^{-}, \mathrm{SO}_{4}^{2-}$, and $\mathrm{HCO}_{3}^{-}$anions in various ratios, as well as a small amount of other ions. Considering that chloride ions are the main activators of pitting corrosion, and sulfate ions have an inhibitory effect on this process, it was necessary to conduct studies on the effect of each of the main components of water on the pitting process. Initially, the effect of chloride ions was studied. In Figure 1 shows the characteristic potentiodynamic curves obtained in an aqueous solution containing only $\mathrm{Cl}^{-}$ ions. With an increase in the chloride ions concentration in the solution, $E_{\mathrm{P}}$ naturally decreases, while the repassivation potential $E_{\mathrm{R}}$ also becomes lower. After changing the 
direction of the potential sweep, in the case of a steadily developing pitting, the current continues to grow for some time and only then decreases. As a rule, the higher the concentration of chloride in the solution, the higher the maximum current can reach. Quite often, with a reverse sweep after a sharp decrease in the current, it is subsequently observed to have a prolonged gentle decline and $E_{\mathrm{R}}$ sometimes shifts up to the initial value of the open circuit potential (Figure 1). The same effect was noted in [6]. Apparently, due to the metastability of the pitting process at the reverse sweep, the boundary where the repassivation $\left(E_{\mathrm{R}}\right)$ occurs is unstable. Table 2 shows the averaged values of the pitting formation and repassivation potentials in solutions with different $\mathrm{Cl}^{-}$contents. As expected, with an increase in the chloride ions concentration, $E_{\mathrm{P}}$ decreases and $E_{\mathrm{R}}$ also decreases, but with a significant scatter relative to the linear trend.

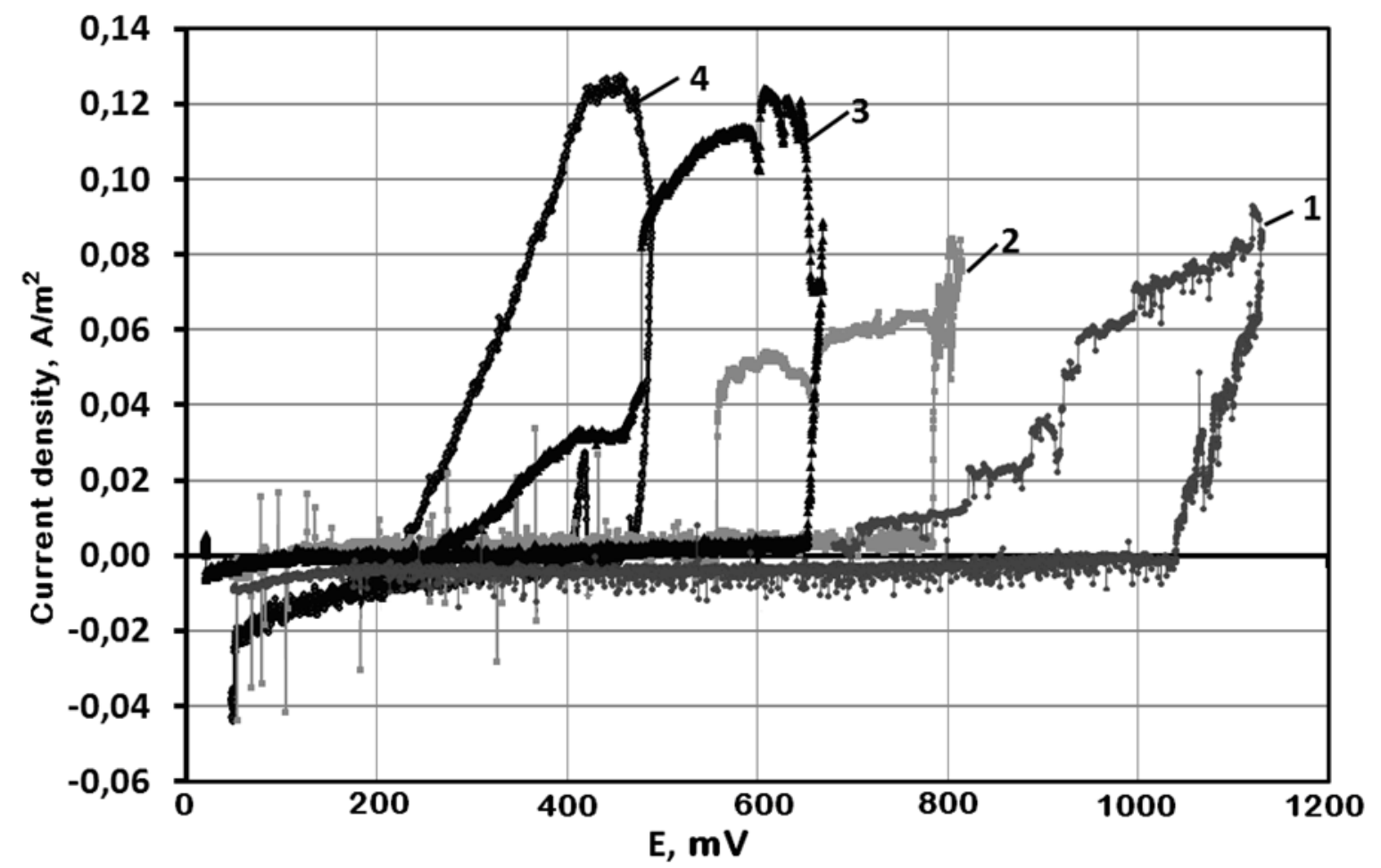

Figure 1. Potentiodynamic curves for steel 321 grade, taken with a sweep rate of $0.1 \mathrm{mV} / \mathrm{s}$ at different content of $\mathrm{Cl}^{-}$in water: (1) $12.5 \mathrm{mg} / \mathrm{L}$, (2) $100 \mathrm{mg} / \mathrm{L}$, (3) $400 \mathrm{mg} / \mathrm{L}$, (4) $2000 \mathrm{mg} / \mathrm{L}$.

Table 2. Average values of $E_{\mathrm{P}}$ and $E_{\mathrm{R}}$ for steel 321 grade in a solution containing only $\mathrm{Cl}^{-}$at $30^{\circ} \mathrm{C}$.

\begin{tabular}{cccccccccccc}
\hline $\mathbf{C l}^{-}, \mathbf{m g} / \mathbf{L}$ & 12.5 & 25 & 50 & 100 & 200 & 300 & 400 & 500 & 1000 & 2000 & 3000 \\
\hline $\boldsymbol{E} \mathbf{P}, \mathbf{m V}$ & 1033 & 1006 & 783 & 778 & 680 & 667 & 620 & 570 & 573 & 490 & 430 \\
\hline $\boldsymbol{E}_{\mathbf{R}}, \mathbf{m V}$ & 760 & 889 & 642 & 561 & 510 & 518 & 390 & 416 & 290 & 262 & 160 \\
\hline
\end{tabular}


The dependence of $E_{\mathrm{P}}$ on the logarithm of the chloride ion concentration is linear with a slope of the straight line $245 \mathrm{mV}$ per decade of $\mathrm{Cl}^{-}$content (Figure 2), which does not contradict the literature $[2,8]$.

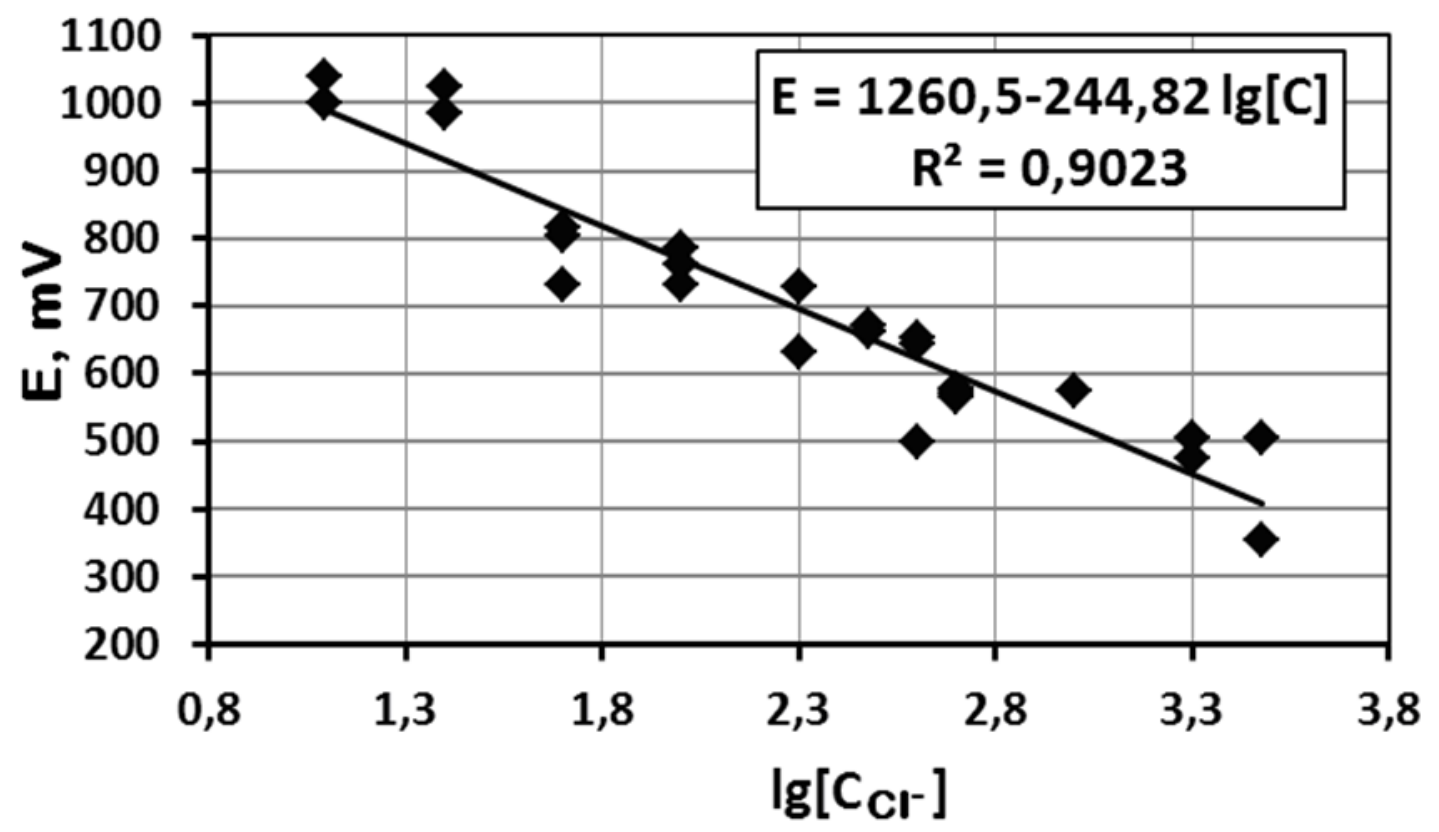

Figure 2. Influence of $\mathrm{Cl}^{-}$concentration on pitting potential. $C$ - chloride ion concentration, $\mathrm{mg} / \mathrm{l} ; E$ - pitting potential, $\mathrm{mV}$.

The presence of a fairly strict semilogarithmic dependence allows extrapolation to be applied to estimate the concentration range where pitting is possible, taking the free corrosion potential and the oxygen reaction potential as reference points. Extrapolation to the region of free corrosion potentials $(E=+200 \mathrm{mV}$, the highest potential observed in the experiments) corresponds to the concentration $21.4 \mathrm{~g} / \mathrm{L}$ of a chloride ion (i.e. $3.5 \% \mathrm{NaCl}$ ). Under these conditions, in the absence of external polarization, pitting corrosion will inevitably occur sooner or later. This chloride concentration is roughly equivalent to seawater, where stainless steel is indeed prone to pitting corrosion. Since the potential of the system cannot turn out to be more positive than the potential of the oxygen and/or chlorine reaction without external polarization, the upper limit of the chloride ions content in water, at which pitting on steel does not appear under natural conditions, can be taken as an extrapolated value from the equation for this potential range. It should be noted that in a solution containing only $50 \mathrm{mg} / \mathrm{L} \mathrm{SO}_{4}^{2-}$ and $100 \mathrm{mg} / \mathrm{l} \mathrm{HCO}-\mathrm{HC}_{3}^{-}$, the anodic process of oxygen evolution on steel 321 grade became noticeable only at potentials above $+1.3 \mathrm{~V}$ due to overvoltage. When extrapolating to this potential, we obtain a boundary concentration $1.45 \mathrm{mg} / \mathrm{L}$ of the chloride. Thus, below this limit, the steel 321 grade can be considered completely resistant to pitting corrosion in water. When the chloride content is in the range 
from $1.45 \mathrm{mg} / \mathrm{L}$ to $21.4 \mathrm{~g} / \mathrm{L}$, pitting can occur both as a result of anodic polarization by an external current and when the efficiency of cathodic depolarization processes increases.

An increase in the cathodic reaction rate is possible in three cases:

- first, it can be observed when stainless steel is in contact with an effective cathode (design factor);

- secondly, as a result of facilitating the actual oxygen depolarization reaction by reducing diffusion restrictions (a factor of reducing the thickness of the diffusion layer);

- third, as a result of the appearance of an additional cathodic process due to a redox reaction caused by the ingress of an oxidant into the medium (for example, the appearance of ferric ions or other oxidizing agents such as dissolved halogens, chromates, peroxides, etc.).

Thus, stainless steel 321 grade can be considered only conditionally resistant to pitting corrosion in river water, and if one or more of the above factors occurs, it can be subject to such corrosion damage.

In addition to the reasons listed above, an increase in the cathodic reaction rate can be local in nature. In many cases, pitting begins near the inclusions present in the steel structure $[5,6]$. In addition to inclusions, other structural factors can also influence, which are not always easy to detect and take into account. Thus, when studying two steels of austenitic class and similar composition, we found that their tendency to pitting in river water differs markedly.

Samples of steel 301 grade were cut from a thick-walled $(7 \mathrm{~mm})$ seamless hot-rolled pipe, and steel 321 grade was taken in the form of $5 \mathrm{~mm}$ sheet. The composition of both alloys corresponded to the standard and is shown in Table 3.

Table 3. Chemical composition of steel 301 grade pipe and steel 321 grade sheet (\% mass.).

\begin{tabular}{cccccccccc}
\hline & $\mathbf{C}$ & $\mathbf{S i}$ & $\mathbf{M n}$ & $\mathbf{N i}$ & $\mathbf{S}$ & $\mathbf{P}$ & $\mathbf{C r}$ & $\mathbf{F e}$ & $\mathbf{T i}$ \\
\hline $\begin{array}{c}301 \text { (X18H9 } \\
\begin{array}{c}\text { Russian Standard } \\
\text { GOST 9940-81) }\end{array}\end{array}$ & $\leq 0.12$ & $\leq 0.3$ & 2 & $8-10$ & $\leq 0.02$ & $\leq 0.035$ & $17-19$ & 70 & - \\
Results of EDXA & - & 0.35 & - & 8.75 & - & - & 18.58 & 71.65 & 0.66 \\
$\begin{array}{c}\text { 321 (X18H10T } \\
\text { Russian Standard } \\
\text { GOST 5632-14) }\end{array}$ & $\leq 0.12$ & $\leq 0.3$ & 2.0 & $9-11$ & $\leq 0.02$ & $\leq 0.035$ & $17-19$ & - & 0.7 \\
\hline
\end{tabular}

Additionally, the steel 301 grade was analyzed for the content of the main alloying elements by X-ray spectral microanalysis. As follows from the given values, the composition of the steels 301 grade, taking into account the refined data based on the results of EDXA, turned out to be practically the same. The microstructure of the alloys also does not differ (Figure 3). Both photos show multiple inclusions of a pinkish tint, located mainly along the 
grain boundaries. Micro X-ray spectral analysis showed that these are titanium carbides or carbonitrides.

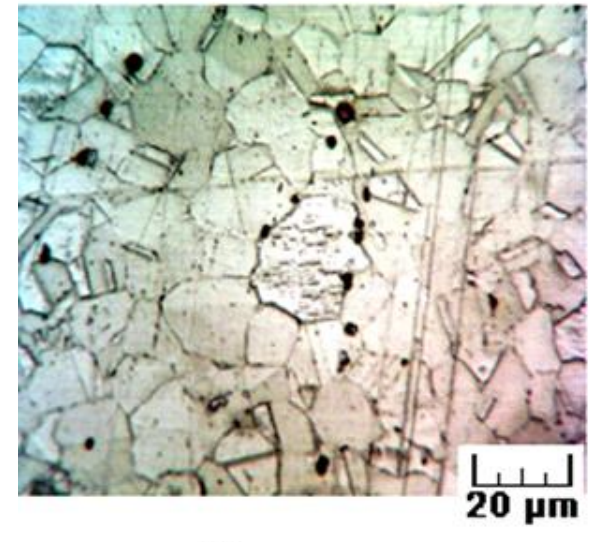

a

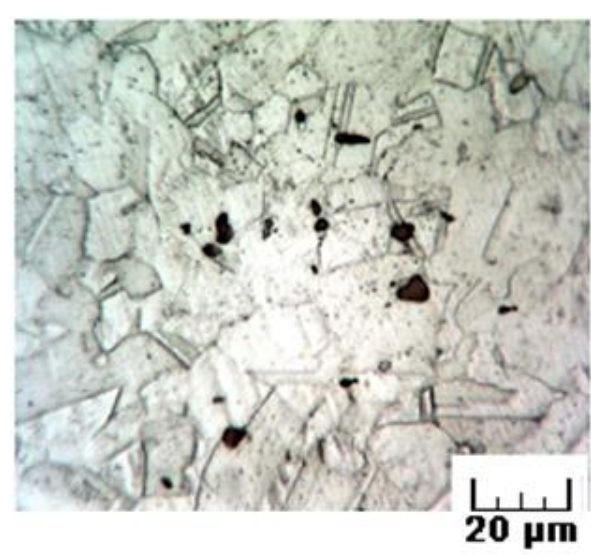

b

Figure 3. Microstructure of the stainless steels: (a) 301 grade pipe, (b) 321 grade sheet.

It is clearly seen in the photographs after corrosion tests that, as a rule, pitting begins with the formation of a thin groove around the non-metallic inclusion, then a wider zone is etched out (Figure 4a) and the inclusion "leaves" the surface (chemically or mechanically), leaving behind a fossa, which can later develop into a full-fledged pitting (Figure 4b).

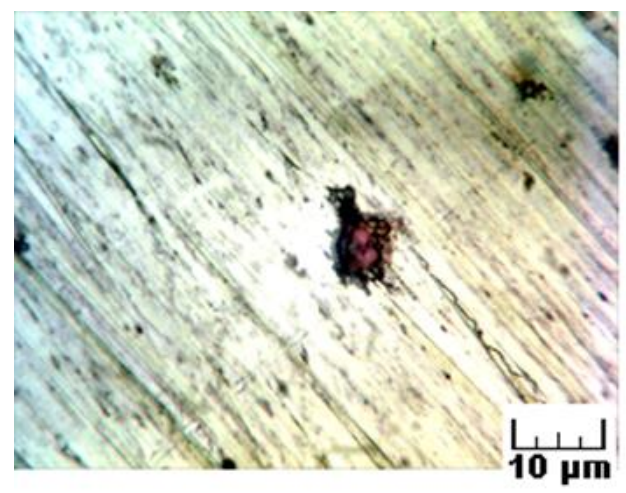

a

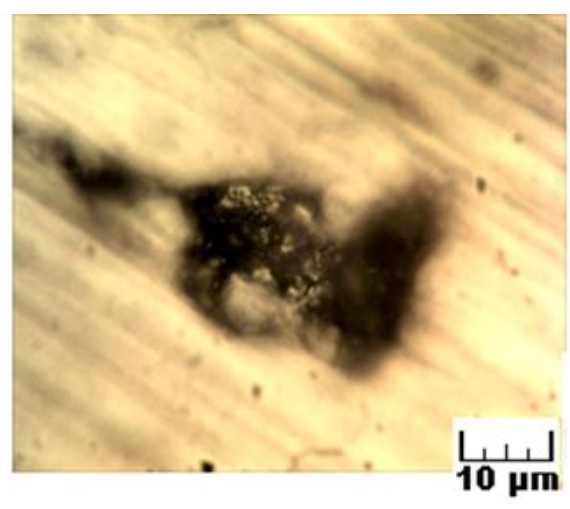

b

Figure 4. Surface after corrosion tests: (a) non-metallic inclusion, (b) micropitting.

Tests of two steels very similar in composition and structure in river water containing $50 \mathrm{mg} / \mathrm{L} \mathrm{Cl}^{-}$showed that steel 301 grade pits in $80 \%$ of cases, while steel 321 grade remains passive up to $E=+1000 \mathrm{mV}$. When the concentration is increased to $100 \mathrm{mg} / \mathrm{L}$ of $\mathrm{Cl}^{-}$, both steels are already pitted by $100 \%$. A similar situation was described in [8]. In the Kama river water, containing $50 \mathrm{mg} / \mathrm{L}$ of chloride and sulfate ions, for the steel 321 grade, the potential $E_{\mathrm{P}}$ was $300 \mathrm{mV}$ more positive than for the steel 301 grade. However, the authors did not pay sufficient attention to finding the reasons for this difference in behavior. Both steels under study belong to the austenitic class, however, the structure of the steel is determined by the 
total effect of all the elements present in it. For a preliminary assessment of the possible phase composition of steels, we used Scheffler's structural diagram [9]. Our calculations based on the diagram of chromium and nickel equivalents showed that pipe steel 301 grade pipe can contain up to $5 \%$ of a ferritic phase in its composition, and sheet steel 321 grade sheet with a high degree of probability is purely austenitic. Additionally, the magnetic properties of these steels were evaluated on the NV9294000 NPO ENT magnetometer. For the sample of pipe steel 301 grade pipe, the magnetic field induction is higher than background values by $2-4 \mu \mathrm{T}$, and for the steel 321 grade sheet only by $0-0.1 \mu \mathrm{T}$. The presence of residual ferrite in the structure of austenitic steel is the result of incomplete transformation of high-temperature $\delta$-ferrite into the $\gamma$-phase. Residual ferrite can adversely affect the pitting tendency of austenitic steels for several reasons. First, according to numerous studies, the resistance of ferritic steels, compared with austenitic steels, is significantly lower both to general and local corrosion [9]. Secondly, internal stresses near the phase boundary can reduce resistance to local lesions. Third, the presence of the second phase inevitably causes a redistribution of the main alloying components (responsible for resistance to pitting) in the border zones.

As already mentioned above, sulfate ions have an inhibitory effect on the pitting process. At a certain $\mathrm{SO}_{4}^{2-} / \mathrm{Cl}^{-}$ratio, this process can be completely inhibited. So in [2] it is argued that in a neutral $0.1 \mathrm{~N} \mathrm{NaCl}$ solution, the required concentration ratio of $\mathrm{Na}_{2} \mathrm{SO}_{4} / \mathrm{NaCl}$ salts should be at least 10 . Natural waters can vary greatly both in the quantitative content of ions and in their ratio. Therefore, the question of whether the $\mathrm{SO}_{4}^{2-} / \mathrm{Cl}^{-}$ratio will be unchanged for the entire studied range of $\mathrm{Cl}^{-}$concentrations requires a separate study. Experiments have shown that the ratio of sulfate and chloride ions, which can prevent the formation of pitting lesions, changes with the concentration of $\mathrm{Cl}^{-}$ions in solution. The higher the concentration of chloride ion in the solution, the greater the number of times its concentration of sulfate ions should be in order to suppress pitting corrosion (Table 4).

Table 4. Sufficient ion concentration ratio $\mathrm{SO}_{4}^{2-} / \mathrm{Cl}^{-}$to prevent pitting corrosion of steel 321 grade in water at $30^{\circ} \mathrm{C}$.

\begin{tabular}{cccc}
\hline $\mathrm{Cl}^{-}, \mathrm{mg} / \mathrm{L}$ & $12.5-100$ & $200-500$ & $1000-3000$ \\
\hline $\mathrm{SO}_{4}^{2-} / \mathrm{Cl}^{-}$ & $1: 1$ & $2: 1$ & $3: 1$ \\
\hline
\end{tabular}

Hydrocarbonate ions $\mathrm{HCO}_{3}^{-}$are usually present in natural fresh water in concentrations from $100 \mathrm{mg} / \mathrm{L}$ to $300 \mathrm{mg} / \mathrm{L}$. No data on the effect of these anions on the pitting corrosion of stainless steels have been found in the literature. In our earlier published work [10], it was shown that hydrocarbonate did not have a noticeable effect on the pitting formation on the ferritic steel 301 grade. For the steel 321 grade under study, a slight decrease in $E_{\mathrm{P}}$ and a decrease in the resistance of the steel to pitting corrosion was observed when the bicarbonate 
ion was introduced into a solution containing only chloride ions or into a solution with an amount of sulfate insufficient to inhibit pitting. If the content of $\mathrm{SO}_{4}^{2-}$ ions in the solution was sufficient to remain the steel passive, then the negative effect of hydrocarbonate leveled out, even if its concentration was 2-4 times higher than the concentration of the inhibitor $\mathrm{SO}_{4}^{2-}$ (Table 5).

Table 5. Potentials $E_{\mathrm{P}}$ and $E_{\mathrm{R}}$ of steel 321 grade sheet at different ratios of chloride, sulfate, and bicarbonate ions in water at $30^{\circ} \mathrm{C}$.

Ion concentration in water

\begin{tabular}{|c|c|c|c|c|}
\hline \multirow{3}{*}{$\frac{\mathrm{Cl}^{-}, \mathrm{mg} / \mathrm{L}}{25}$} & \multirow{3}{*}{$\frac{\mathrm{HCO}_{3}^{-}, \mathrm{mg} / \mathrm{L}}{-}$} & \multirow{3}{*}{$\frac{\mathrm{SO}_{4}^{2-}, \mathrm{mg} / \mathrm{L}}{-}$} & \multirow[t]{2}{*}{$E_{\mathrm{P}}, \mathbf{m V}$} & \multirow[t]{2}{*}{$E_{\mathrm{R}}, \mathrm{mV}$} \\
\hline & & & & \\
\hline & & & 1006 & 889 \\
\hline 25 & 100 & - & 795 & 628 \\
\hline 25 & - & 25 & \multicolumn{2}{|c|}{ No pitting } \\
\hline 25 & 100 & 25 & \multicolumn{2}{|c|}{ No pitting } \\
\hline 50 & - & - & 783 & 462 \\
\hline 50 & 100 & - & 765 & 615 \\
\hline 50 & - & 50 & \multicolumn{2}{|c|}{ No pitting } \\
\hline 50 & 100 & 50 & \multicolumn{2}{|c|}{ No pitting } \\
\hline 100 & - & - & 825 & 560 \\
\hline 100 & - & 50 & 894 & 135 \\
\hline 100 & 100 & 100 & 810 & 475 \\
\hline 100 & - & 100 & \multicolumn{2}{|c|}{ No pitting } \\
\hline 100 & 100 & 100 & \multicolumn{2}{|c|}{ No pitting } \\
\hline
\end{tabular}

\section{Conclusion}

Thus, austenitic stainless steel 321 grade is subject to the risk of pitting corrosion in lowmineralized water with a chloride ion content of $1.45 \mathrm{mg} / \mathrm{L}$ and higher. With an increase in chloride concentration, the resistance of steel decreases. The presence of sulfate ions increases the resistance of steel to pitting corrosion. With a sufficient sulfate content, pitting corrosion does not occur at all. The threshold ratio of sulfate inhibitor to activator chloride for pitting protection depends on the concentration of the activator. The higher the concentration of the chloride activator, the higher the sulfate inhibitor ratio $\mathrm{SO}_{4}^{2-} / \mathrm{Cl}^{-}$is required to prevent pitting. The presence of bicarbonate in water in the absence of sulfate insignificantly reduces the resistance of steel to pitting; however, with a sufficient amount 
of sulfate in solution, it completely inhibits both the harmful effect of chloride and bicarbonate.

\section{References}

1. I.I. Zamaletdinov and A.N. Smetkin, Influence of molybdenum of the welded seam on pitting corrosion of steel 12X18H9, Korroz.: Mater., Zashch. (Corrosion: materials, protection), 2016, no. 8, 17-25 (in Russian).

2. I.L. Rosenfeld, Corrosion and protection of metals, Moscow, Metallurgy, 1969, 448 (in Russian).

3. D.A. Moreno, A.M. Garcna, C. Ranninger and B. Molina, Pitting corrosion in austenitic stainless steel water tanks of hotel trains, Rev. Metal. (Madrid, Spain), 2011, 47, no. 6, 497-506.

4. O.V. Tambova, V.V. Kravtsov, N.M. Fatkhiev and M.G. Karavaichenko, Analysis of the causes of corrosion of tank structures made of aluminum alloys in contact with aqueous media, Bashkir Chem. J., 2007, 14, no. 3, 98-101 (in Russian).

5. A.I. Shcherbakov, I.V. Kasatkina, I.G. Korosteleva and L.P. Kornienko, Pitting corrosion of austenitic stainless steel $12 \mathrm{X} 18 \mathrm{H} 9$ in low-mineralized (river) water, Korroz.: Mater., Zashch. (Corrosion: materials, protection), 2018, no. 6, 32-34 (in Russian).

6. L.I. Freiman and L.Ya. Kharitonova, On the potentiodynamic determination of the potentials of pitting and repassivation of steel, Prot. Met., 1972, no. 6, 693-695 (in Russian).

7. A.V. Ryabchenkov, V.I. Gerasimov, I.L. Kharina and N.S. Ershov, On electrochemical methods for determining the tendency of chromium steels to pitting corrosion in chloride solutions, Prot. Met., 1973, no. 4, 408-411 (in Russian).

8. I.I. Zamaletdinov and I.N. Baryshnikov, On the characteristic potentials of pitting corrosion of compact and powder steels, Korroz.: Mater., Zashch. (Corrosion: materials, protection), 2016, no. 5, 7-14 (in Russian).

9. N.D. Tomashov and G.P. Chernova, Corrosion theory and corrosion resistant structural alloys, Moscow, Metallurgy, 1983, 414 (in Russian).

10. A.I. Shcherbakov, V.N. Dorofeeva, I.G. Korosteleva, I.V. Kasatkina and L.P. Kornienko, Pitting corrosion of stainless steel 40X13 in low mineralized water, Korroz.: Mater., Zashch. (Corrosion: materials, protection), 2020, no. 4, 17-20 (in Russian). doi: 10.31044/1813-7016-2020-0-4-17-20 